\title{
TRANSCERVICAL FEMORAL FRACTURE
}

\section{A Review of 195 Patients Treated by Sliding Nail-plate Fixation}

\author{
J. T. Brown and G. Abrami, Glasgow, Scotland \\ From the Western Infirmary, Glasgow
}

Until 1956 Smith-Petersen nailing was the method of choice at Glasgow Western Infirmary for treatment of displaced fractures of the femoral neck in adults. A survey of the results in eighty-three consecutive fractures so treated gave little satisfaction, with bone union in 54 per cent of patients followed for more than one year. Despite the better claims published from time to time since the introduction of trifin nailing in 1931 (Smith-Petersen, Cave and Vangorder 1931) this experience seemed comparable to the results from other centres (EyreBrook and Pridie 1941; Charnley, Blockey and Purser 1957).

From 1957 onwards a sliding nail-plate with shaft fixation, evolved by one of us (J. T. B.), replaced the simple trifin nail technique and it appeared to provide better three-point fixation of the fracture. The principle has become increasingly popular in a variety of forms since the concept of additional shaft fixation was proposed and described by Dickson (1953). Sliding nail-plate fixation has been the method of choice at this centre for treatment of intracapsular femoral neck fractures with displacement from 1957 until the present time. Experience to date gives no cause to abandon the method which has been employed on more than 400 occasions without selection of patients and by all members of the staff. At the same time a review and follow-up scheme was planned as a long-term project to study the natural history of the fracture in adults after treatment by this one standard method and to analyse, so far as numbers permitted, various factors of possible significance in determining success or failure.

This paper presents some of these findings and conclusions from a study of a consecutive series of 195 high femoral neck fractures treated between January 1957 and December 1961. Undisplaced, impacted abduction fractures and basal fractures have been excluded from the survey. In drawing conclusions the main pitfall, as always, lies in placing too much emphasis on deductions from small groups where many factors are to be assessed, and this may well be a valid criticism of parts of the present review. Our results are of possible value at least in showing trends towards a pattern which may become clearer as the criteria for assessment of results in this problem become established. The factors considered here include the type and displacement of fracture, the patient's age and sex, delay till operation, and the shearing angle of the fracture, which was assigned a role of some importance by Pauwels (1935) and of slight importance by Linton (1944) and others. Consideration has also been made of the quality of reduction and nailing and the presence of posterior comminution, which may have predisposed to failure after simple trifin fixation. At the same time an attempt has been made to apply fixed indices to the femoral head and neck on post-reduction radiographs for determination of the fracture level in the neck and for measurement of valgus or varus reduction. Radiographic studies have been maintained during follow-up to determine the onset and incidence of late superior segmental collapse, a complication after successful osteosynthesis which may pass unobserved unless follow-up is prolonged into the second and third year after operation.

\section{METHOD OF FIXATION}

The appliance illustrated in Figure 1 has the advantage of simplicity, ease of introduction, tensile strength adequate for the loads imposed, and effective control of rotation as well as of varus displacement; yet it allows progressive impaction, if necessary, at the fracture site without 
risk of the nail perforating the capital articular surface. It differs only in detail from other appliances which embody similar principles (Pugh 1955, Schumpelick and Jantzen 1955) and it achieves its effect by channelling the deforming forces on the head into an impacting force between the fracture surfaces delivered along the neck axis. It consists of a trifin nail sliding in a circular barrel set at an angle of 135 degrees to a three-hole plate, the proximal end of the barrel being crimped into the trifin shape to prevent rotation. A split ring washer in the nail head provides an easily adjustable degree of friction against occasional premature

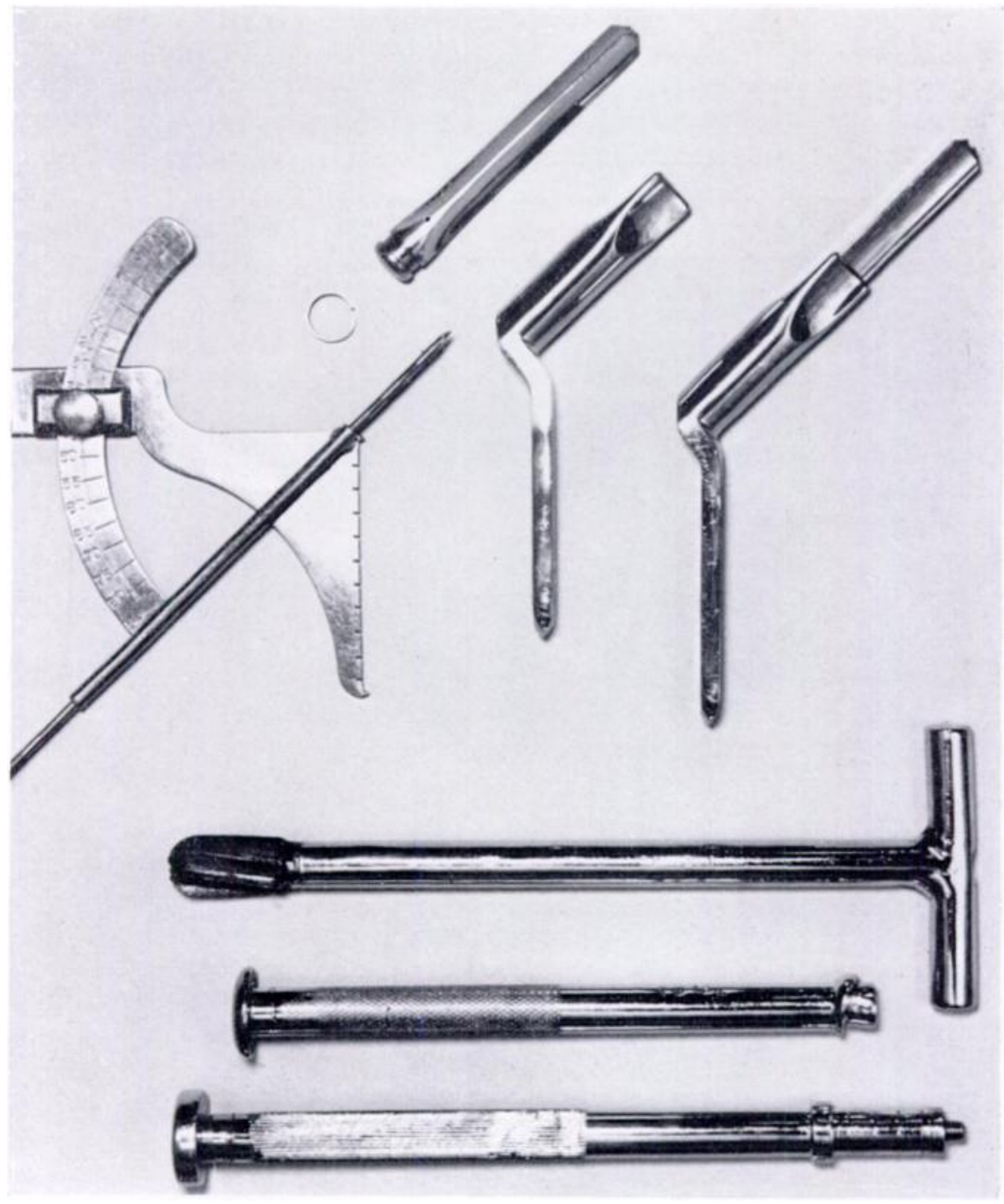

FIG. 1

Sliding nail-plate components and instruments required for insertion.

extrusion from an excessively porotic femoral head, and also helps to prevent late central migration of the nail, which was observed to occur against gravity on two occasions when the nail had inadvertently been driven through the articular cortex and then withdrawn.

The standard guide-wire technique for insertion is no more difficult than for a fixed angle nail-plate. It requires a 45 degrees angled director, a cannulated bone reamer to perforate the outer femoral cortex, and a cannulated and graduated punch. The bracket has proved strong enough for its task; in more than 400 nailings only one is known to have fractured from 
fatigue at the angle. This fracture occurred in the fourth year after operation in an ambulant patient in whom the apparently stable but doubtfully united fracture redisplaced completely after plate failure. On two further occasions the screw heads gave way during ambulation because the nail had jammed in the barrel, so preventing its sliding action. The subsequent addition of a depth stop to the cannulated punch prevented this. Fixation to the femoral shaft by three screws has proved adequate provided the trifin nail can slide under moderate compression; this is routinely checked before insertion and adjusted by slightly opening or closing the split ring washer if necessary.

The aim has been to achieve anatomical rather than valgus reduction, to place the nail centrally in the head and to select the shortest nail which will reach to within a quarter of an inch of the articular cortex (Fig. 2). Particular care is taken to avoid perforating the articular cortex because this hard shell of bone alone presses the trifin nail down into the barrel during subsequent impaction or settling at the fracture line. In practice the final guide wire is measured and its intraosseous length minus half an inch indicates the suitable nail. The bracket is of

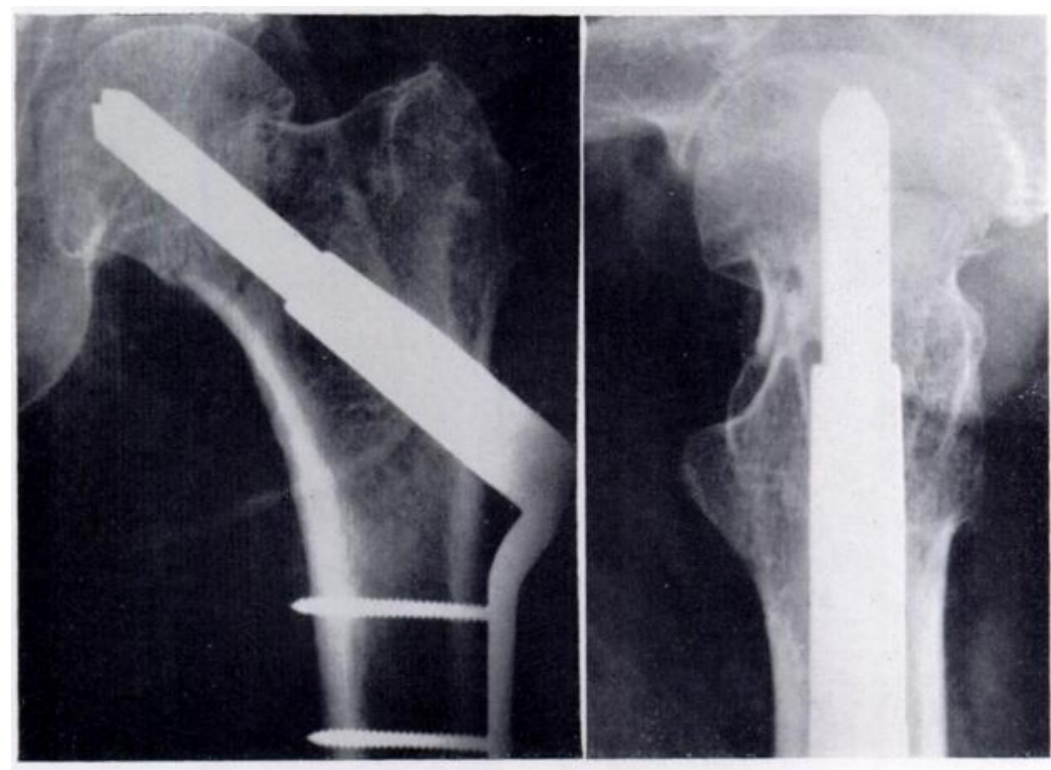

Fig. 2

Antero-posterior and lateral radiographs of a femoral neck fracture with sliding nail-plate in position.

standard size and the complete assembly is inserted as one unit until the plate lies flush on the femur, the final punching home of the nail inside the barrel being checked on an anteroposterior radiograph with the graduated punch in place. The nominal period for avoidance of weight bearing after operation has been twelve weeks throughout the series, except for seventeen patients who were allowed to walk after two weeks without notable ill effect.

\section{ASSESSMENT OF RESULTS}

The results were assessed in three grades: 1) united;2) failed; and 3) position holding, union doubtful.

"United" here implies bony union of the fracture with radiographic evidence of trabeculation visible across the fracture line. Accepting the known difficulty of radiographic assessment, we still regard bone union across the fracture line as the best index of successful treatment. Its recognition is essentially radiographic, and although some films were made available by practitioners in local hospitals the great majority of patients in the series were 
reviewed by members of our staff at out-patient clinics. The ultimate assessment of all radiographic features was done by a combined personal study by the authors of the whole sequence of radiographs for each patient from admission to last review. The classification of the fracture as united or otherwise was more reliably made during this retrospective study.

"Failed" in the series indicates recurrence of the fracture deformity or progressive displacement of such degree that a salvage procedure became necessary. It does not include patients with late superior segmental collapse after bone union.

An appreciable number of patients continued to be ambulant with fixation of the fracture maintained-often despite a slowly deteriorating position-and without clear evidence of bone union even in the second year after operation. Continued follow-up showed that some such cases became failures whereas in others the fracture ultimately united. When follow-up ceased during the indeterminate phase the result has been assessed as "position holding, union doubtful " or, for brevity in some tables, as " holding."

Patients were placed in the first and last categories only after a follow-up of one year or more, but the "failed" group includes all failures occurring at any interval after operation; indeed, 84 per cent of the failures occurred within the first year. Undisplaced, impacted abduction and basal fractures were excluded from the series as were pathological fractures.

TABLE I

DURATION OF Follow-UP fOR “ UNITED” AND

“ Holding, Union Doubtful" Groups

\begin{tabular}{|c|c|c|}
\hline $\begin{array}{c}\text { Follow-up } \\
\text { (years) }\end{array}$ & United & $\begin{array}{c}\text { Holding, } \\
\text { union doubtful }\end{array}$ \\
\hline Over 1 & 21 & 12 \\
\hline Over 2 & 38 & 2 \\
\hline Over 3 & 26 & 1 \\
\hline Over 4 & 15 & - \\
\hline Total & 100 & 15 \\
\hline
\end{tabular}

"Deaths" in the tables refers to mortality and includes all deaths occurring within the first two months after operation. The series includes three patients with significant wound infection, in one of whom the infection was responsible for failure at six months. It was relatively mild in two others although still present when they died from other causes in the eighth and tenth weeks after operation.

Follow-up-Among "united" and "position holding, union doubtful" groups, follow-up ranged from twelve months to five and a half years. For these two groups the follow-up by years is shown in Table I. Altogether 14 per cent of patients were lost to the series by inadequate follow-up. This quite low figure was obtained only by the cooperation of our colleagues, by domiciliary radiography when necessary and, in some instances, by the help of distant practitioners who faithfully submitted high quality radiographs from urban, West Highland and Hebridean hospitals.

\section{RESULTS}

In 195 patients with displaced femoral neck fractures, unselected and treated by closed manipulation and sliding nail-plate fixation, the results in men and women are shown in Table II. The mortality was 10.8 per cent (twenty-one patients) and the loss by inadequate follow-up 14 per cent (twenty-eight patients). In the remaining 146 patients available to survey the results of treatment were: 1) united 68.5 per cent ; 2) failed 21.2 per cent; 3) position holding, union 
TABLE II

Results for Men and Women in 195 Patients

\begin{tabular}{|c|c|c|c|c|c|c|c|}
\hline & $\begin{array}{c}\begin{array}{c}\text { Number } \\
\text { of } \\
\text { patients }\end{array} \\
\end{array}$ & United & Holding & Failed & Deaths & $\begin{array}{c}\text { No } \\
\text { follow-up }\end{array}$ & $\begin{array}{l}\text { Late } \\
\text { segmental } \\
\text { collapse }\end{array}$ \\
\hline Men & 40 & 24 & 3 & 3 & 5 & 5 & 7 \\
\hline Women . & 155 & 76 & 12 & 28 & 16 & 23 & 21 \\
\hline Total & 195 & 100 & 15 & 31 & 21 & 28 & 28 \\
\hline
\end{tabular}

TABLE III

Results Related to Age in Forty Men

\begin{tabular}{|c|c|c|c|c|c|c|c|}
\hline $\begin{array}{c}\text { Age } \\
\text { group } \\
\text { (years) }\end{array}$ & $\begin{array}{c}\text { Number } \\
\text { of } \\
\text { patients }\end{array}$ & United & Holding & Failed & Deaths & $\begin{array}{c}\text { No } \\
\text { follow-up }\end{array}$ & $\begin{array}{c}\text { Late } \\
\text { segmenta } \\
\text { collapse }\end{array}$ \\
\hline Under 60 & 10 & 9 & - & - & - & 1 & 1 \\
\hline $60-64$ & 6 & 4 & 2 & - & - & - & 2 \\
\hline $65-69$ & 3 & - & - & 1 & 1 & 1 & - \\
\hline $70-74$ & 8 & 4 & - & 1 & 1 & 2 & 1 \\
\hline $75-79$ & 5 & 4 & - & 1 & - & - & 1 \\
\hline $80-84$ & 6 & 3 & 1 & - & 2 & - & 2 \\
\hline Over 84 & 2 & - & - & - & 1 & 1 & - \\
\hline Total & 40 & 24 & 3 & 3 & 5 & 5 & 7 \\
\hline
\end{tabular}

TABLE IV

Results Related to Age in 155 Women

\begin{tabular}{|c|c|c|c|c|c|c|c|}
\hline $\begin{array}{l}\text { Age } \\
\text { group } \\
\text { (years) }\end{array}$ & $\begin{array}{c}\text { Number } \\
\text { of } \\
\text { patients }\end{array}$ & United & Holding & Failed & Deaths & $\begin{array}{c}\text { No } \\
\text { follow-up }\end{array}$ & $\begin{array}{c}\text { Late } \\
\text { segmental } \\
\text { collapse }\end{array}$ \\
\hline Under 60 & 4 & 3 & - & 1 & - & - & - \\
\hline $60-64$ & 13 & 11 & - & - & - & 2 & 2 \\
\hline $65-69$ & 20 & 8 & 3 & 5 & 1 & 3 & 1 \\
\hline $70-74$ & 35 & 22 & 4 & 5 & 2 & 2 & 9 \\
\hline $75-79$ & 41 & 18 & - & 10 & 7 & 6 & 3 \\
\hline $80-84$ & 30 & 10 & 4 & 6 & 3 & 7 & 4 \\
\hline Over 84 & 12 & 4 & 1 & 1 & 3 & 3 & 2 \\
\hline Total & 155 & 76 & 12 & 28 & 16 & 23 & 21 \\
\hline
\end{tabular}


doubtful $10 \cdot 3$ per cent. In the 100 patients with established bone union twenty-eight patients subsequently developed late superior segmental collapse of the femoral head.

\section{FACTORS ANALYSED IN RELATION TO END RESULTS}

Age and sex-The usual preponderance of women patients was evident in this series with a women to men ratio of $3.9: 1$, the greatest incidence of women patients and of fractures occurring in the seventies (Fig. 3). This ratio might have reflected the known preponderance of old women in the population. When, however, the sex ratios of the age groups in the fracture series were compared with the ratios for similar sex and age groups in the general population derived from the city of Glasgow census for 1961, it became evident that there was a distinct predilection for femoral neck fracture in elderly women far beyond the maximum 2.1:1 preponderance of women in the general population. In this fracture series the ratio of women to men reached a maximum of $8 \cdot 2: 1$ in the seventy-five to seventy-nine years age group (Fig. 4). When the results were analysed by age and sex groups there was evidence of markedly better prognosis for men in general and for women under sixty-five (Tables III and IV).

The highest failure rate was observed in women over seventy-five where 59 per cent united, 32 per cent failed and 9 per cent remained doubtful, and the results were not much better for women between sixty-five and seventy-five.

Type of fracture-In radiographic studies displacement of the fractures was recognised in four grades: 1) no displacement; 2) impaction in abduction; 3) displacement of the neck into lateral rotation with or without posterior impaction and comminution (Fig. 5); 4) lateral rotation deformity with relative adduction, shortening and coxa vara (Fig. 6). As recorded above, only fractures in Grade 3 and Grade 4 have been considered in this series. These grades correspond broadly to the classification of Garden (1961) but difficulty was found at times in distinguishing a severe Garden Type III displacement with rotation from the above Grade 4. In the present series the numerically large Grade 4 probably includes some fractures which, for purposes of comparison, might have been classed as Garden Type III. Despite this possible favourable loading, the present series still gave evidence of a better prognosis amongst Grade 3 fractures where displacement was essentially a lateral rotation one alone (Table V).

TABLE V

Results Related to Degree of Fracture Displacement in 195 Patifnts

\begin{tabular}{|c|c|c|c|c|c|c|c|}
\hline Displacement & $\begin{array}{c}\text { Number } \\
\text { of } \\
\text { patients }\end{array}$ & United & Holding & Failed & Deaths & $\begin{array}{c}\text { No } \\
\text { follow-up }\end{array}$ & $\begin{array}{c}\text { Late } \\
\text { segmental } \\
\text { collapse }\end{array}$ \\
\hline Grade 3 & 26 & 19 & 1 & 1 & 2 & 3 & 4 \\
\hline Grade 4 & 169 & 81 & 14 & 30 & 19 & 25 & 24 \\
\hline Total & 195 & 100 & 15 & 31 & 21 & 28 & 28 \\
\hline
\end{tabular}

Results were distinctly inferior among 169 with Grade 4 displacement. Within that group analysis confirmed a greater failure rate among women. This was particularly so amongst women over sixty-five with Grade 4 fractures of whom 58 per cent united, 32 per cent failed and 10 per cent remained doubtful (Fig. 7).

Any series which includes a high proportion of women over sixty-five and of fractures with Grade 4 displacement will compare unfavourably with a series in which the converse conditions obtain. These results seem merely to confirm clinical experience. In this series 


\section{Number of \\ Fractures}

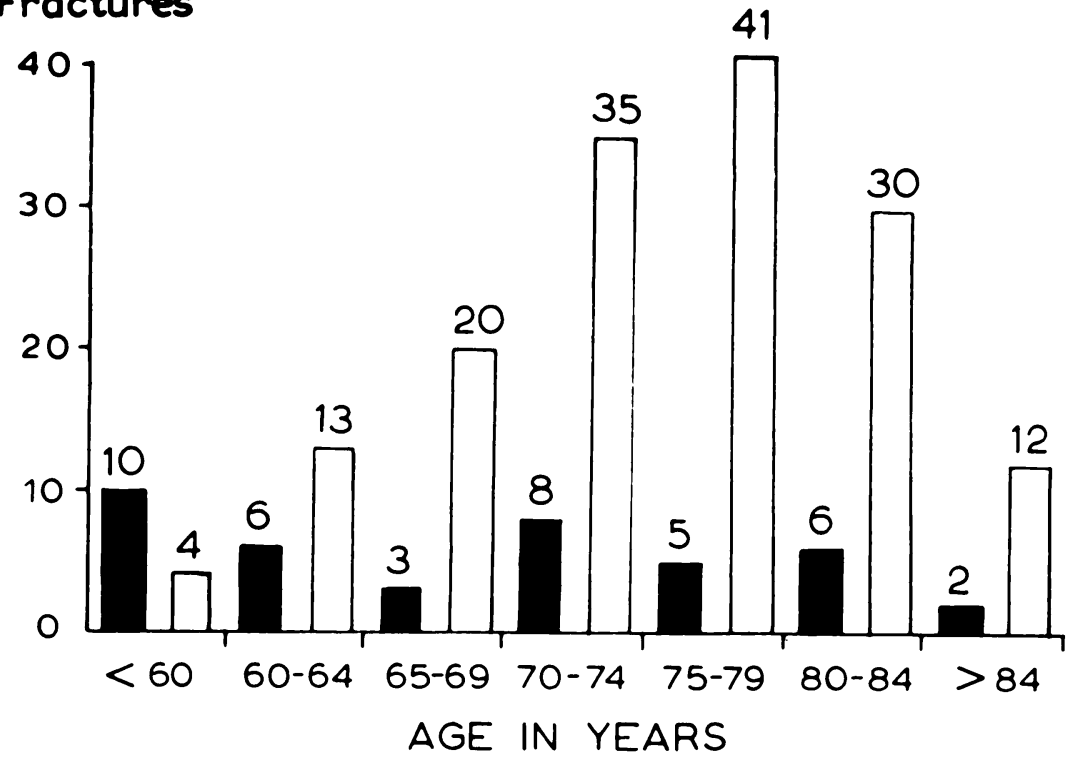

$\square$ MEN $\square$ WOMEN

FIG. 3

The age and sex distribution in 195 patients.

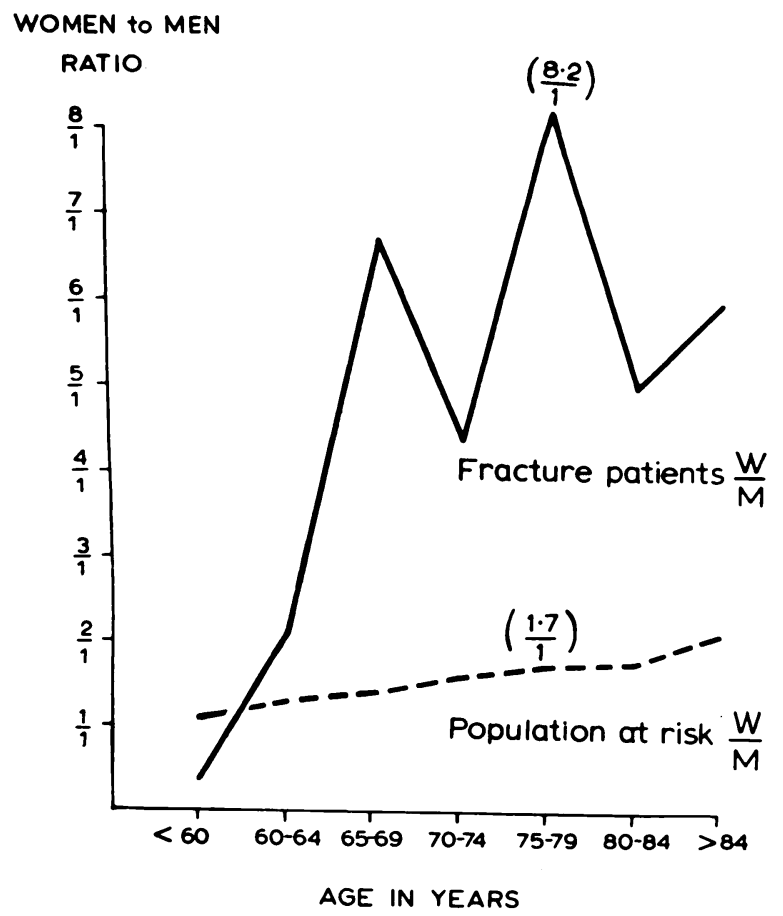

FIG. 4

Graph showing the ratio of women to men by age groups in the fracture series and in the population at risk. 
they also indicate that the femoral neck fracture, although acknowledged a troublesome one in old age and in childhood (McDougall 1961), is not such a serious problem in adults below the age of sixty-five. A similar trend was recorded by Hargadon and Pearson (1963) in 100
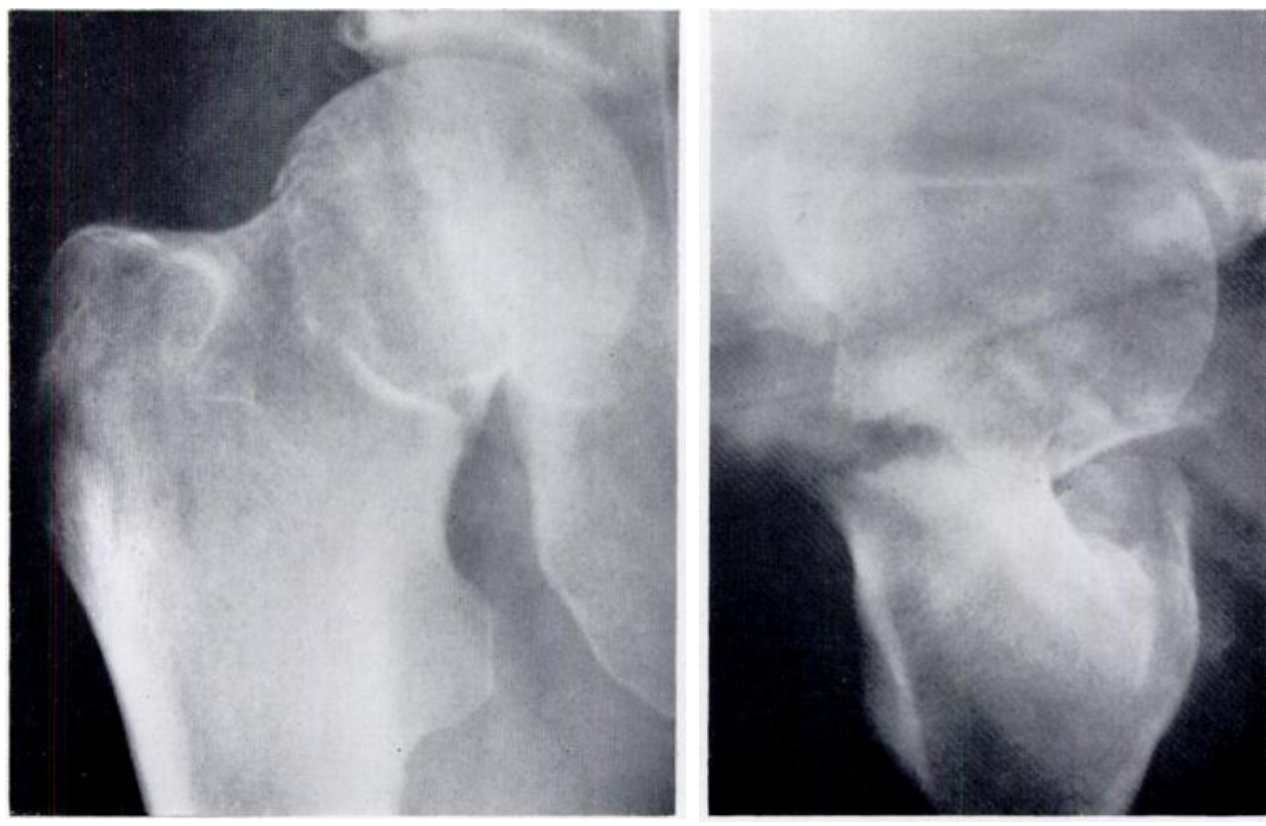

Fig. 5

Antero-posterior and lateral radiographs of a fracture with Grade 3 displacement.
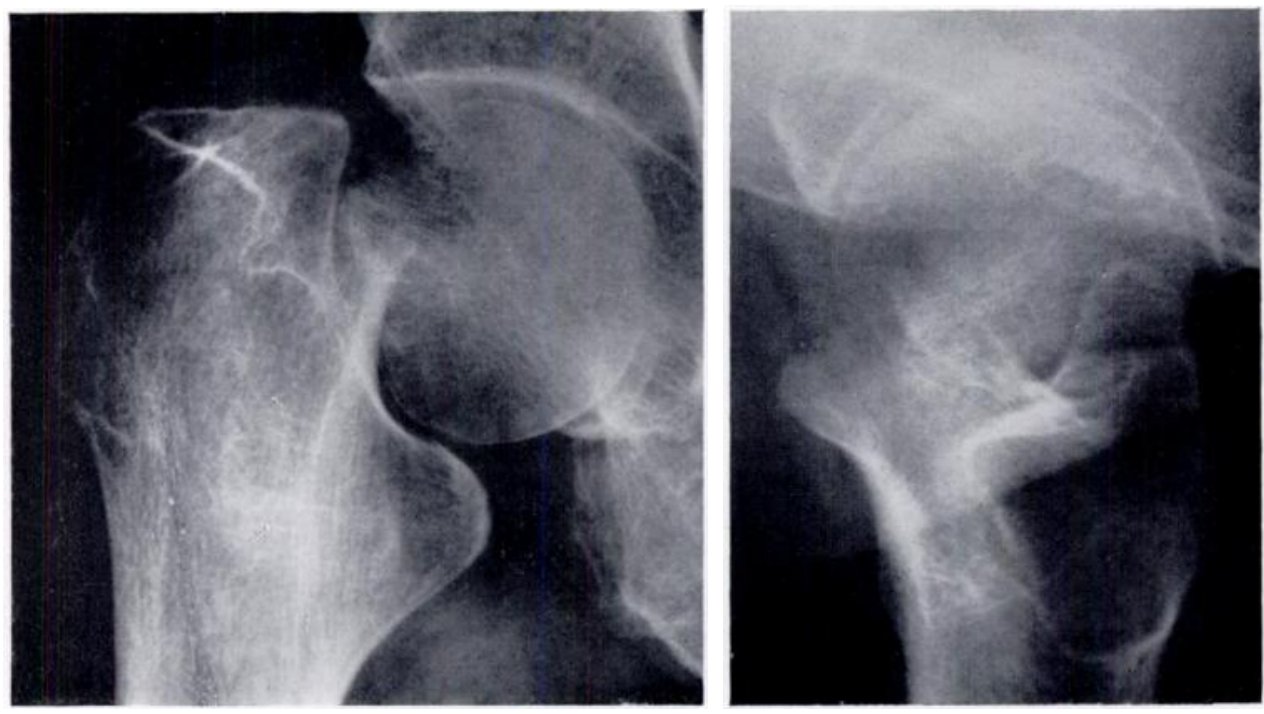

Fig. 6

Antero-posterior and lateral radiographs of a fracture with Grade 4 displacement.

fractures treated by the Charnley compression screw. In their series twelve of the fourteen patients under sixty obtained bone union.

In the analysis of subsequent factors it has been attempted, whenever numbers permitted, to assess their effect only within the limited group of Grade 4 fractures in women over sixty-five. Altogether 123 patients came into this category. Thirty-three of them were

VOL. 46 B, NO. 4, NOVEMBER 1964 

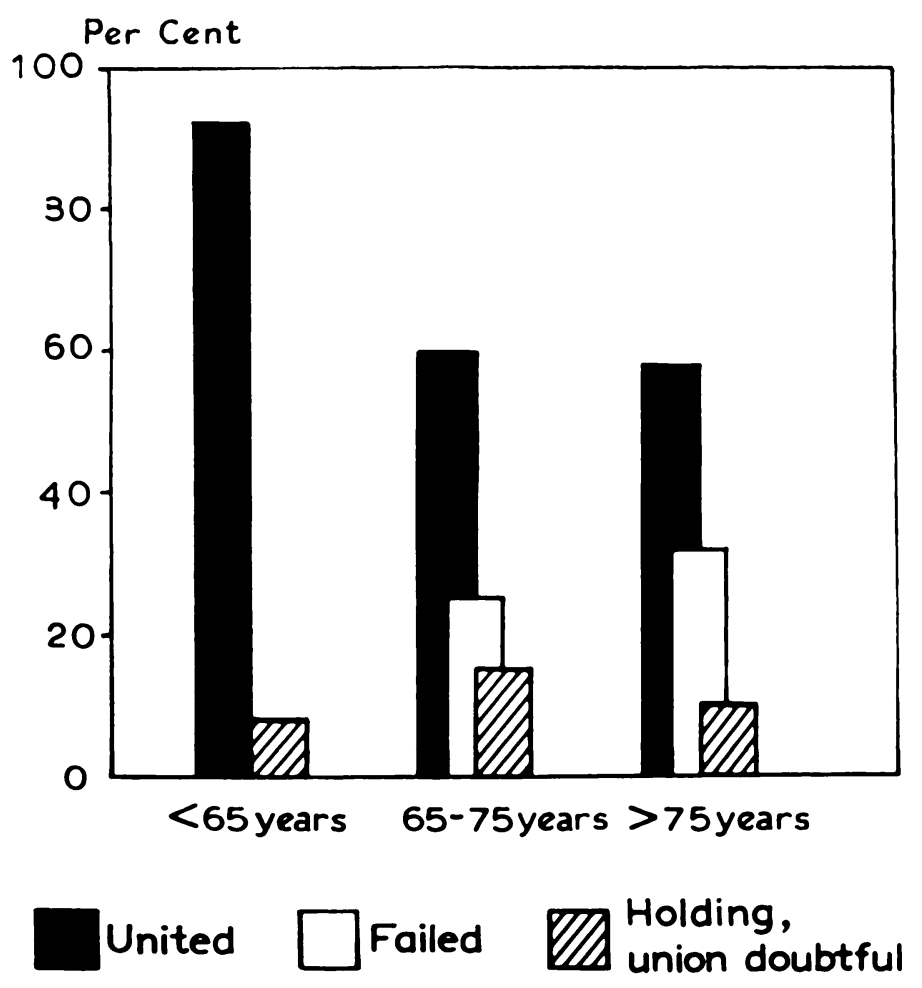

FIG. 7

Showing the results by age groups in 103 women with Grade 4 fracture displacement.

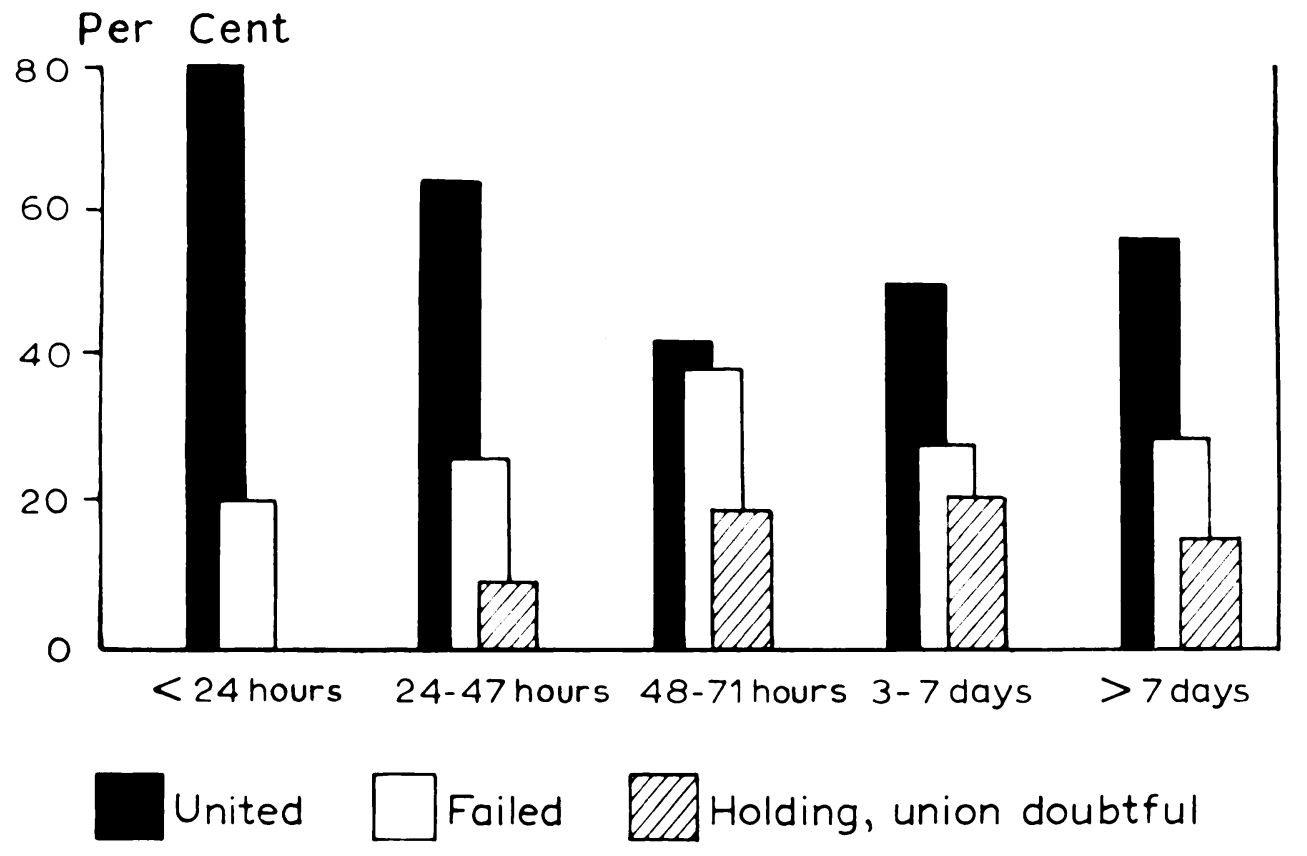

FIG. 8

The results related to operative delay in ninety women over 65 years with Grade 4 fracture displacement. 
inadequately followed or died, leaving a group of ninety available for further analysis. This stringent selection seemed necessary not only to provide the most severe test of treatment but also to provide the most uniform conditions for the assessment of other factors.

Delay before operation-Delay between injury and admission to hospital is seldom under direct control and it has not been our practice to conduct operative nailing as an emergency. In this series patients remained with the leg supported in simple traction until the first available theatre session. This could entail a variable delay at week-ends of twelve hours to three days. Delay of a week or more was sometimes caused by ill-health. Amongst the ninety women over sixty-five with Grade 4 fracture displacement there was evidence of direct benefit by early operation when this had been done within twenty-four hours from the time of injury. In these patients 80 per cent united and 20 per cent failed. When the operative delay was more than two days, less than 50 per cent united, rather more than 30 per cent failed and some 20 per cent were holding with union doubtful (Fig. 8). If these observations can subsequently be confirmed the rather disturbing implication may arise that the fracture should be treated as an emergency.

TABLE VI

Results Related to the Quality of Reduction in Ninety Women oVer Sixty-Five with Grade 4 Fracture Displacement

\begin{tabular}{|l|c|c|c|c|c|}
\hline \multicolumn{1}{|c|}{ Reduction } & $\begin{array}{c}\text { Number } \\
\text { of } \\
\text { patients }\end{array}$ & $\begin{array}{c}\text { United } \\
(\text { per cent })\end{array}$ & $\begin{array}{c}\text { Holding } \\
(\text { per cent })\end{array}$ & $\begin{array}{c}\text { Failed } \\
(\text { per cent })\end{array}$ & $\begin{array}{c}\text { Late } \\
\text { segmental } \\
\text { collapse } \\
(\text { per cent })\end{array}$ \\
\hline Excellent & 4 & 75 & 25 & 0 & 33 \\
\hline Satisfactory & 55 & $65 \cdot 5$ & $12 \cdot 5$ & 22 & 33 \\
\hline Unsatisfactory & 31 & 45 & 10 & 45 & $28 \cdot 5$ \\
\hline
\end{tabular}

Quality of reduction-From radiographs taken at operation the reduction in twelve cases was anatomical; in 122 it was acceptable with some malalignment; and in sixty-one it was unsatisfactory with marked displacement in any axis. The favourable effect of good reduction was evident in this series particularly when applied to the testing group of Grade 4 fractures in women over sixty-five. In thirty-one cases with bad reductions only 45 per cent united in contrast to those with an acceptable reduction in whom 65.5 per cent united (Table VI). Yet somewhat unexpectedly the incidence of late segmental collapse after union in each group was fairly uniform ( 28.5 per cent and 33 per cent) and would appear to discount the importance of ischaemic necrosis as the sole responsible factor.

Technique-No significant influence on results was found when related to varying positions of the trifin nail in the head except that an unduly short nail in the head, by failing to provide adequate fixation, gave a poor result.

Comminution-Amongst Grade 3 and Grade 4 fractures crushing of the posterior capital margin, or posterior or inferior comminution of the cortex, was observed in 125 patients. No adverse influence was observed on the results. In this mixed group 68 per cent united, 20.5 per cent failed, 11.5 per cent were holding, and the incidence of late segmental collapse after union was 20 per cent.

Level of fracture-Basal fractures of the femoral neck have not been included but some further differentiation was attempted within the series by direct measurement on the post-reduction radiograph with the limb medially rotated. For each patient three points were marked (Fig. 9): A) the centre of the head by the method of Wiberg (1939) using a concentrically inscribed plastic sheet superimposed on the radiograph; B) the mid-point of a line joining

VOL. 46 B, NO. 4, NOVEMBER 1964 
the upper and lower margins of the femoral neck fracture surface; C) the tip of the vastus ridge at the base of the greater trochanter. This last point was at times subject to some error when the ridge was poorly defined. For practical purposes it made a difference of some millimetres in measurement and of a few degrees in angle. These errors were considered to be unimportant as account was to be taken only of gross differences.

TABLE VII

Results Related to Level of Fracture (Fracture-neck Ratio) in Ninety Women over Sixty-five with Grade 4 Fracture Displacement

\begin{tabular}{|c|c|c|c|c|c|}
\hline $\begin{array}{l}\text { Level of } \\
\text { fracture }\end{array}$ & $\begin{array}{l}\text { Number of } \\
\text { patients }\end{array}$ & $\begin{array}{c}\text { United } \\
\text { (per cent) }\end{array}$ & $\begin{array}{l}\text { Holding } \\
\text { (per cent) }\end{array}$ & $\begin{array}{c}\text { Failed } \\
\text { (per cent) }\end{array}$ & $\begin{array}{c}\text { Late } \\
\text { segmental } \\
\text { collapse } \\
\text { (per cent) }\end{array}$ \\
\hline Less than $1: 5.5$ & 11 & $63 \cdot 5$ & 9 & $27 \cdot 5$ & 57 \\
\hline $1: 5 \cdot 5$ to $1: 3.5$ & 59 & $54 \cdot 5$ & $13 \cdot 5$ & 32 & 31 \\
\hline More than $1: 3.5$ & 20 & 70 & 10 & 20 & $21 \cdot 5$ \\
\hline
\end{tabular}

TABLE VIII

Results Related to Angle of Reduction (Axis Angle) in Ninety Women over Sixty-five with Grade 4 Fracture Displacement

\begin{tabular}{|c|c|c|c|c|c|}
\hline $\begin{array}{c}\text { Axis angle } \\
\text { (degrces) }\end{array}$ & $\begin{array}{l}\text { Number of } \\
\text { patients }\end{array}$ & $\begin{array}{c}\text { United } \\
\text { (per cent) }\end{array}$ & $\begin{array}{l}\text { Holding } \\
\text { (per cent) }\end{array}$ & $\underset{(\text { per cent })}{\text { Failed }}$ & $\begin{array}{c}\text { Late } \\
\text { segmental } \\
\text { collapse } \\
\text { (per cent) }\end{array}$ \\
\hline Less than 140 . & 27 & $55 \cdot 5$ & $7 \cdot 5$ & 37 & 33 \\
\hline $140-160$. & 43 & 65 & 14 & 21 & 25 \\
\hline More than 160 & 20 & 50 & 15 & 35 & 50 \\
\hline
\end{tabular}

TABLE IX

Results Related to Fracture/Shaft Angle (Shearing Angle) in Ninety Women over Sixty-five with Grade 4 Fracture Displacement

\begin{tabular}{|l|c|c|c|c|c|}
\hline $\begin{array}{c}\text { Fracture/shaft } \\
\text { angle } \\
(\text { degrees })\end{array}$ & $\begin{array}{c}\text { Number of } \\
\text { patients }\end{array}$ & $\begin{array}{c}\text { United } \\
(\text { per cent })\end{array}$ & $\begin{array}{c}\text { Holding } \\
(\text { per cent })\end{array}$ & $\begin{array}{c}\text { Failed } \\
(\text { per cent })\end{array}$ & $\begin{array}{c}\text { Late } \\
\text { segmental } \\
\text { collapse } \\
(\text { per cent })\end{array}$ \\
\hline Less than 25. & 17 & 65 & 12 & 23 & 18 \\
\hline $25-40 \cdot$ & 58 & 55 & 14 & 31 & 31 \\
\hline Over 40. & 15 & $66 \cdot 5$ & 7 & 26.5 & 50 \\
\hline
\end{tabular}

The linear measurements between points $\mathrm{A}$ and $\mathrm{B}$ and between $\mathrm{B}$ and $\mathrm{C}$ expressed as a ratio and designated as the fracture-neck ratio, were used to provide an index of the level of the fracture in the femoral neck. The mean and the standard deviation of these fracture-neck ratios in the whole series were calculated. Three groups of fracture level were obtained, the middle group (ratios $1: 5.5$ to $1: 3.5$ ) being selected by including all ratios within one standard deviation of the mean. 
On this basis, amongst Grade 4 fractures in women over sixty-five no significant difference in the failure rate was evident between the numerically large group of middle level fractures (ratio $1: 5.5$ to $1: 3.5$ ) and the small group of very high subcapital fractures (ratio less than $1: 5.5$ ) where the failure rates were 32 per cent and 27.5 per cent respectively (Table VII). The number of very high fractures was probably too small for valid comparison but it was interesting that this group contained the highest incidence of late segmental collapse (57 per cent) after union. Not unexpectedly the group of relatively low neck fractures (ratio greater than $1: 3.5$ ) gave more favourable results with 20 per cent failure and 21.5 per cent late segmental collapse.

Measured angle of reduction (axis angle) - The angle subtended by the three points mentioned above (Fig. 9) was used as an index of reduction on the same antero-posterior radiograph or, when some shift had occurred during pinning, on the post-nailing radiograph. By measuring this axis angle on the excellent reductions and from tracing the patient's fracture on a

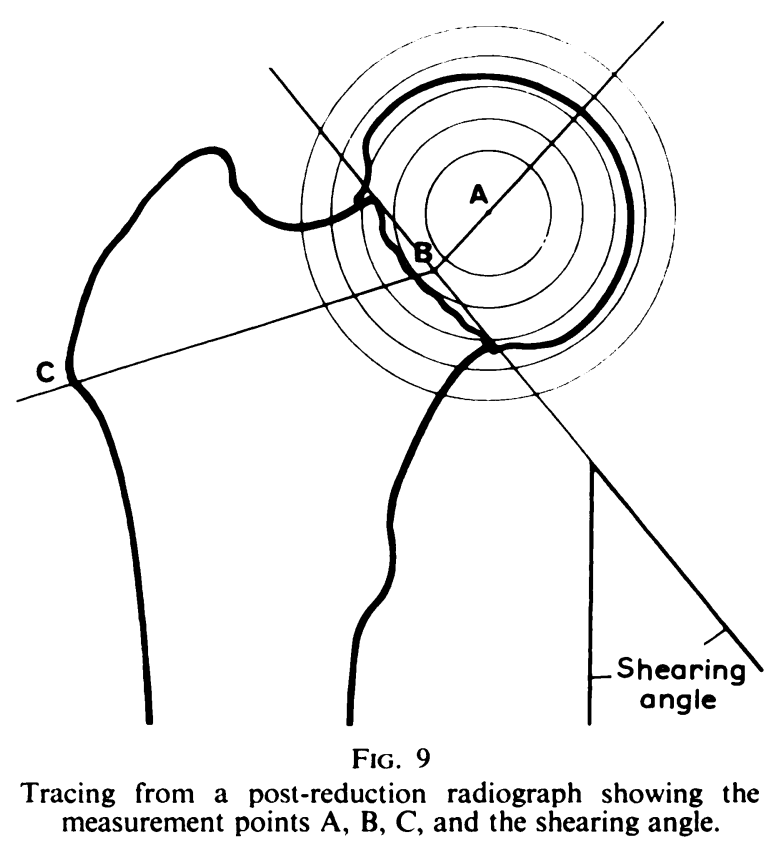

radiograph of the normal hip in medial rotation it was established that angles of about 150 degrees represented near anatomical reduction. An axis angle below 140 degrees indicated obvious valgus reduction or downward shift of the neck on the head. Angles over 160 degrees and in extreme cases beyond 180 degrees indicated varus reduction or persistent upward displacement of the neck.

Analysis was made within these three broad groups and applied particularly to Grade 4 fractures in women over sixty-five where it was found that the normal group showed bone union in 65 per cent of patients, the valgus group in 55.5 per cent and the varus (incompletely reduced) group in 50 per cent of patients (Table VIII).

Shearing angle-The angle of the fracture line in the neck may be important when mechanical fixation is imperfect. Authors have not unanimously confirmed the assertion by Pauwels (1935) that fractures making an angle of more than 50 degrees to the horizontal were unlikely to unite. In this series the complement of Pauwels' angle - the fracture to shaft angle-was measured on each post-reduction radiograph as an index of this shearing angle (Fig. 9). The majority of fractures showed a shearing angle in the range of 25 degrees to 40 degrees but to clarify the interpretation, comparison was made of results at the two extremes above and below this middle range and analysed in the Grade 4 fractures in women over sixty-five.

VOL. 46 B, NO. 4 , NOVEMBER 1964 
Slight benefit was evident in the group with a relatively large fracture-shaft angle when 66.5 per cent united. It was not materially less in the most vertical fractures with a shearing angle of less than 25 degrees when 65 per cent united. This latter was only slightly below the series average and did not confirm that vertical fractures are unlikely to unite (Table IX). The numbers involved in the two extreme angle groups are small and may make these findings inconclusive.

\section{AVASCULAR NECROSIS OF THE FEMORAL HEAD}

Popular belief attributes a large measure of responsibility for failure of union to this phenomenon. It is commonly believed to exist in large or small degree in most intracapsular fractures. It may be established during the period before operation and may be determined by the nature and severity of the injury. The only certain guides to the incidence of avascular

\section{Number of}

Fractures
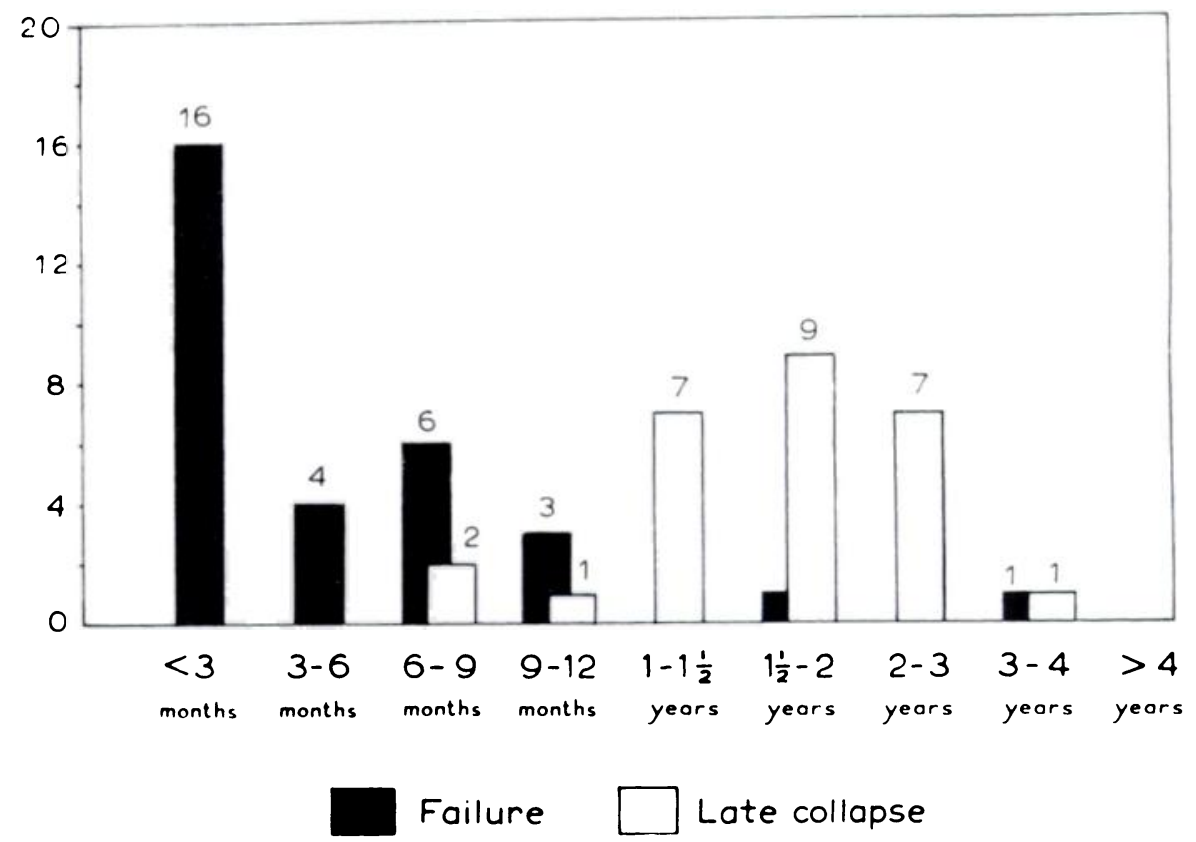

FIG. 10

Showing the interval between nailing and failure or late segmental collapse.

necrosis, at present, are in retrospect by histological examination of material excised some time after injury and by the incontrovertible radiographic evidence of late superior segmental collapse after union (Barnes 1962). It may be suspected when progressive severe impaction of the femoral neck into the head goes on steadily over a number of months (Charnley et al. 1957). Biopsy at operation is seldom helpful because the histological changes of bone ischaemia become recognisable with certainty only after an interval of about twenty-one days (Catto 1964).

In failed nailings - From the thirty-one failed fractures in this series twenty-six femoral heads were submitted to histological examination. All the specimens showed severe or total ischaemia of the head.

In late superior segmental collapse-Twenty-eight fractures in the series with established bone union later developed superior segmental collapse (Table II). Eight of these were excised for 
painful disability and five of the specimens examined histologically. All five showed a uniform histological pattern with clear evidence of an initial severe ischaemia of the head fragment and with subsequent revascularisation across a healed fracture. The revascularising process, however, had failed to reach the most proximal and superior quadrant of the femoral head during the years before collapse.

If this histological pattern of gross ischaemia is accepted as representative for all failed fractures and for all fractures showing late segmental collapse after union then the summation of these two groups within a series will provide, at least, a minimum estimate of the incidence of gross avascular necrosis after fracture. On this basis fifty-nine of the femoral heads in the series (approximately 30 per cent) must have been grossly ischaemic, yet almost half of these were associated with ultimate bony union. This takes no cognisance of partly ischaemic heads which no doubt existed and which probably contributed to the "position holding, union doubtful" group. Ischaemic necrosis, even total ischaemia, of the head fragment is undoubtedly important but it can hardly be the sole cause of failure after nailing.

The time at which failure occurred in thirty-one failed fractures is shown in Figure 10 together with the time of onset of late segmental collapse in twenty-eight united fractures. The highest incidence of failure occurred within the first three months after operation (sixteen patients), while segmental collapse most often became evident after eighteen to twenty-four months and on one occasion during the fourth year after operation.

Ischaemia in relation to operative delay-In nineteen patients (Grade 4 fractures in women over sixty-five) treated within twenty-four hours of injury there were four failures and five with late segmental collapse after union. Judged on a summation basis, therefore, this group must have contained at least 47 per cent fractures (nine out of nineteen) in which the head was grossly ischaemic. In forty-seven patients with delay before operation of more than two days, sixteen failed and seven showed late segmental collapse giving a comparable incidence of gross ischaemia in this group of about 50 per cent.

The difference appears insignificant and hardly reflects the different rates of union in these two groups. If valid, this observation lends further support to the belief that ischaemia of the head fragment is not solely responsible for the end result.

Late segmental collapse in relation to other factors- No significant relationship was observed between the occurrence of late segmental collapse and delay before operation, the quality of reduction (Table VI) or the presence of comminution. In women over sixty-five with Grade 4 fracture displacement the incidence of late segmental collapse was 33 per cent-a little above the series average ( 28 per cent) but not strikingly so. A lower incidence of late segmental collapse and indeed of failure was evident for all age and sex groups amongst Grade 3 fractures. This no doubt reflected a less severe soft-tissue trauma when displacement was essentially an external rotation one alone. The above figures, showing little significant variation in the incidence of ischaemia relative to different factors, tended to confirm our belief that the ischaemic condition is established at the time of injury and that its occurrence is not so dependent on factors arising afterwards.

Nature of late segmental collapse-The sequestrated segment of the femoral head after late collapse varied in extent from a deep wedge to a thin cortical shell extending usually from just medial to the superior acetabular margin to the region of the fovea. It had no fixed relation to the position of the nail-tip beyond involving the superior and anterior weight-bearing surface. Histological examination indicated that collapse most often occurred through dead trabeculae rather than at the zone of advancing, perhaps static, revascularisation. The condition has deliberately been referred to as late segmental collapse in this paper rather than as late segmental necrosis. Ischaemic necrosis of the femoral head appears to be established at the time of injury and to be of gross extent. It is the collapse after union which is late and segmental. The impression gained has been that this late collapse occurs as a physical fatigue fracture of dead trabeculae after prolonged weight bearing rather than as a

VOL. $46 \mathrm{~B}$, NO. 4, NOVEMBER 1964 
"softening-up" process by advancing blood vessels. The time lapse before its clinical onset may, therefore, be directly related to the strength and number of trabeculae present in the femoral head at the time of injury.

\section{DISCUSSION}

In this series the results of treatment by sliding nail-plate fixation appear to have been influenced by the age and sex of the patient; the degree of displacement of the fracture: operative delay of more than twenty-four hours; and by the accuracy of coaptation in reduction. The predominance of these factors in any fracture series will influence the end results and must be allowed for when comparison is attempted. The presence of comminution at the fracture and the vertical shearing angle of the fracture line appeared to be of much less significance in this series. Gross ischaemia of the femoral head was a constant finding in the failed fractures but also existed in 28 per cent of the united group, becoming apparent much later as segmental collapse. The ischaemic episode seems likely to be established at the time of injury, but the ultimate fate of the ischaemic fragment may be determined by the physical strength of the bone at the time of injury and by a combination of other factors mentioned above.

The only factors amenable to surgical control seem to be: 1) early operation (within twenty-four hours if possible); 2) careful coaptation of the fragments; and 3) efficient three-point fixation. In this series most patients were nominally permitted to bear weight three months after operation but in a recent series surveyed by Abrami and Stevens (1964) in which walking was encouraged after two weeks no adverse effect was evident in the results.

There may be a place for routine primary replacement arthroplasty in the management of Grade 4 fractures in women over seventy-five years, but not in women under sixty-five and not in men of any age unless other complications exist.

The observations made in this paper can, at best, be only of a tentative nature because they are based on a relatively small number of patients. The points which do emerge, however, may prove helpful by indicating the need for uniform standards of comparison if cumulative information is to be gained from retrospective studies made at different centres, as suggested by Nicoll (1963). It seems clear that valid information can only be obtained by analysing, in the first instance, large series in which the method of treatment remains uniform. If such analysis confirms the significance of the factors described above, then the same criteria can be applied in subsequent series to provide valid comparison between different methods of fixation.

\section{SUMMARY}

1. A review of 195 patients with displaced intracapsular fractures of the femoral neck treated by a sliding nail-plate appliance has been presented.

2. The highest failure rate was evident in fractures in women over seventy-five with Grade 4 displacement.

3. The effect of various concomitant factors has been analysed in relation to the end results.

4. Observations have been made on avascular necrosis, its incidence amongst the failures and its association with late segmental collapse after fracture union.

We are indebted to our orthopaedic colleagues at the Western Infirmary for allowing us to study their patients. Our special thanks are due to Professor Roland Barnes for his help and encouragement and to Dr Mary Catto for the histological information. We gratefully acknowledge our debt to Miss J. L. Sandford and Miss P. Jackson for much clerical assistance, to Mr G. Donald for the illustrations and figures and to Mrs M. Clark for the Tables. The apparatus has been manufactured to our requirement and supplied by Messrs Down Bros. and Mayer \& Phelps Ltd., London.

This work was undertaken with the assistance of a grant from the Department of Health for Scotland. 


\section{REFERENCES}

Abrami, G., and Stevens, J. (1964): Early Weight Bearing after Internal Fixation of Transcervical Fracture of the Femur. Preliminary Report of a Clinical Trial. Journal of Bone and Joint Surgery, 46-B, 204.

Barnes, R. (1962): The Diagnosis of Ischaemia of the Capital Fragment in Femoral Neck Fractures. Journal of Bone and Joint Surgery, 44-B, 760.

CATto, M. (1964): Personal communication.

Charnley, J., Blockey, N. J., and Purser, D. W. (1957): The Treatment of Displaced Fractures of the Neck of the Femur by Compression. Journal of Bone and Joint Surgery, 39-B, 45.

Dickson, J. A. (1953): The "Unsolved” Fracture. A Protest Against Defeatism. Journal of Bone and Joint Surgery, 35-A, 805.

Eyre-Brook, A. L., and Pridie, K. H. (1941): Intracapsular Fractures of the Neck of the Femur. Final Results of 75 Consecutive Cases Treated by the Closed Method of Pinning. British Journal of Surgery, 29, 115.

GARDEN, R. S. (1961): Low-angle Fixation in Fractures of the Femoral Neck. Journal of Bone and Joint Surgery, 43-B, 647.

Hargadon, E. J., and Pearson, J. R. (1963): Treatment of Intracapsular Fractures of the Femoral Neck with the Charnley Compression Screw. Journal of Bone and Joint Surgery, 45-B, 305.

Linton, P. (1944): On the Different Types of Intracapsular Fractures of the Femoral Neck. A Surgical Investigation of the Origin, Treatment, Prognosis and Complications in 365 Cases. Acta Chirurgica Scandinavica 90 , Supplementum 86.

McDougall, A. (1961): Fracture of the Neck of the Femur in Childhood. Journal of Bone and Joint Surgery, 43-B, 16.

Nicoll, E. A. (1963): The Unsolved Fracture. Journal of Bone and Joint Surgery, 45-B, 239.

Pauwels, F. (1935): Der Schenkelhalsbruch, ein mechanisches Problem. Grundlagen des Heilungsvorganges. Prognose und kausale Therapie. Stuttgart: Ferdinand Enke.

Pugh, W. L. (1955): A Self-Adjusting Nail-Plate for Fractures about the Hip Joint. Journal of Bone and Joint Surgery, 37-A, 1,085.

Schumpelick, W., and Jantzen, P. M. (1955): A New Principle in the Operative Treatment of Trochanteric Fractures of the Femur. Journal of Bone and Joint Surgery, 37-A, 693.

Smith-Petersen, M. N., Cave, E. F., and Vangorder, G. W. (1931): Intracapsular Fractures of the Neck of the Femur. Treatment by Internal Fixation. Archives of Surgery, 23, 715.

WiBERG, G. (1939): Studies on Dysplastic Acetabula and Congenital Subluxation of the Hip Joint with Special Reference to the Complication of Osteo-Arthritis. Acta Chirurgica Scandinavica 83, Supplementum 58. 